\title{
Erratum to: Challenges in minimizing the adverse effects of cannabis use after legalization
}

\author{
Wayne Hall ${ }^{1,2}$
}

Published online: 19 September 2015

(C) Springer-Verlag Berlin Heidelberg 2015

\section{Erratum to: Soc Psychiatry Psychiatr Epidemiol (2015) 50:1013-1015 DOI 10.1007/s00127-015-1067-5}

Unfortunately, due to a publisher's error, the information linking this Editorial to the commented review article "Psychosocial sequelae of cannabis use and implications for policy: findings from the Christchurch Health and Development Study" by David M. Fergusson et al. was omitted during the publication process.

The missing information reads as follows:

\section{Comment on:}

This Editorial comments on the review article "Psychosocial sequelae of cannabis use and implications for policy: findings from the Christchurch Health and Development Study" by David M. Fergusson et al., Soc Psychiatry Psychiatr Epidemiol 2015. doi:10.1007/s00127-015-1070-x.

Please excuse any inconveniences caused. The publisher apologizes for the error.

The Publisher

The online version of the original article can be found under doi:10.1007/s00127-015-1067-5.

Wayne Hall

w.hall@uq.edu.au

1 K Floor Mental Health Centre, Royal Brisbane and Womens' Hospital Site, The University of Queensland Centre for Youth Substance Abuse Research, Herston, QLD 4029, Australia

2 National Addiction Centre, Kings College London, London, UK 